\title{
MODELAGEM DE PRESSÕES DE POROS NA ÁREA CENTRAL DA BACIA DE SANTOS
}

\author{
PORE PRESSURE MODELING IN CENTRAL AREA OF SANTOS BASIN, BRAZIL \\ João Paulo PICOLINI ${ }^{1}$, Hung Kiang CHANG ${ }^{2}$ \\ ${ }^{1}$ Petrobras. Email: jpp1795@gmail.com \\ ${ }^{2}$ LEBAC - Laboratório de Estudo de Bacias - IGCE - UNESP, Rio Claro - SP. Email: chang @ rc.unesp.br \\ Introdução \\ Objetivo \\ Contexto Geológico \\ Pressões de Poros \\ Materiais e Métodos \\ Construção dos Modelos \\ Resultados \\ Discussão dos Resultados \\ Conclusões \\ Agradecimentos \\ Referências
}

\begin{abstract}
RESUMO - Foram estudadas as pressões de poros (PP) numa área central da Bacia de Santos. Atenção especial foi dedicada à Sequência K90, Santoniano ao Campaniano, constituída pelas formações Juréia e Itajaí-Açu, a qual possui pelitos (Folhelho-Selo) e arenitos (Reservatório Principal) com acumulações de gás. Os modelos 1D permitiram quantifica as PP dos poços, verificar sua distribuição espacial e estratigráfica e sugerir as causas da sobrepressão (pressão anormalmente elevada). Na Sequência K90 constatou-se duas zonas com sobrepressão: ZPA Principal e ZPA Secundária, enquanto nas sequências mais antigas (K82-86 e K88) identificaram-se zonas de ocorrência localizadas (ZPA-2a e ZPA-2b). A ZPA Principal engloba a Acumulação Principal de gás da área (800 m de espessura) e apresenta gradiente de pressão de poros (GPP) de até 12,6 ppg (zona de gás) e 11,7 ppg (aquífero). O gás acumulado é o elemento principal para o desenvolvimento da sobrepressão. Ele elevou o GPP na zona de gás, em relação ao aquífero, e sua coexistência com a água reduziu o fluxo de fluidos no Folhelho-Selo, retardando a equalização das pressões. Camadas menos permeáveis e falhas selantes reduziram ainda mais o fluxo de fluidos e contribuíram com a manutenção das PP elevadas.

Palavras-chave: Pressão de poros. Sobrepressão. Perfis geofísicos. Bacia de Santos. Petróleo.
\end{abstract}

ABSTRACT - Pore pressures (PP) have been studied in a central area of the Santos Basin, Brazil, Special attention was given to the K90 Depositional Sequence, Santonian to Campanian age, composed by two formations - Juréia and Itajaí-Açu. The last is made of pelitic rocks (Shale-Seal) and sandstones (Main Reservoir) with gas accumulations. The 1D models allowed to quantify pore pressures, verify their distribution and suggest probable causes for overpressure (anormal high pressure). A Main Zone of Anormal High Pressure (ZPA) and a Secondary ZPA were detected in the K90 Sequence and, zones of minor importance (ZPA-2a e ZPA-2b), were detected in the older sequences (K82-86 and K88). The Main ZPA encompass the Main Accumulation of gas of the area (800m of thickness) and presents a pore pressure gradient (GPP) up to 12,6 ppg (gas zone) and 11,7 ppg (water zone). Gas is the main element to generate overpressure. PP has raised up in the gas zone (buoyance effect) and Gas and water coexistence must have reduced the hydraulic conductivity of the Shale-Seal, retarding equalization of the pressures. Less permeable layers and sealing faults further reduced the flow of fluids, contributing to the elevation of pore pressures.

Keywords: Pore pression. Overpression. Well log profiles. Santos Basin. Petroleum.

\section{INTRODUÇÃO}

Atualmente, a Exploração e Produção de Petróleo (E\&P) direcionam-se para áreas com maior complexidade geológica e risco operacional, necessitando conciliar economicidade, segurança operacional, respeito à sociedade e ao meio-ambiente. Neste contexto, é crescente a importância atribuída ao estudo das pressões em subsuperfície, com destaque para as Pressões de Poros (PP) (Rocha \& Azevedo,
2009). Existem muitas ocorrências de PPs anormalmente elevadas (sobrepressão) nas bacias sedimentares ao redor do mundo, inclusive na Bacia de Santos (Pecten-MarathonShell, 1978; Law \& Spencer, 1998; Granitoff, 2004; Domingues, 2008; Picolini, 2017). Sua quantificação é fundamental para a análise evolutiva de uma bacia, modelagem de sistemas petrolíferos e perfuração segura de poços.

\section{OBJETIVO}

Neste trabalho foram estudadas as pressões de poros (PP) numa área localizada no centro da Bacia de Santos (Figura 1), onde ocorrem sobrepressão em rochas da Formação Itajaí-Açu.

$\mathrm{O}$ objetivo do trabalho foi quantificar as PPs

em poços perfurados pela Petrobras, estabelecer a distribuição das Zonas de Pressão Anormal (ZPA), onde ocorre sobrepressão, e identificar as possíveis causas para o desenvolvimento das pressões anormais. 


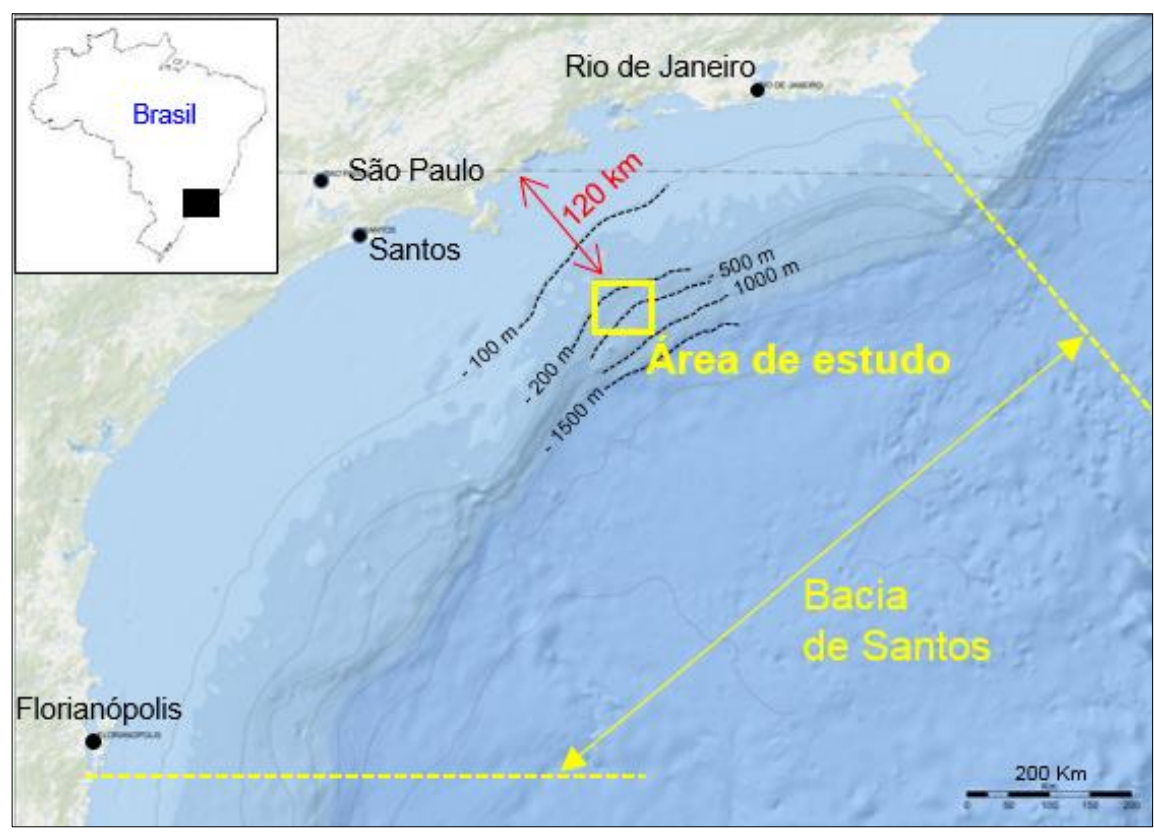

Figura 1 - Localização da área de estudo. As isóbatas estão destacadas pelas linhas pretas tracejadas.

\section{CONTEXTO GEOLÓGICO}

A Bacia de Santos localiza-se na costa sudeste do Brasil (Figura 1). Originou-se a cerca de 132 Ma em decorrência da separação entre a América do Sul e a África (Chang et al., 1992; Cobbold et al., 2001). Seu embasamento é composto por rochas ígneas e metamórficas précambrianas da Faixa Ribeira (Heibron et al., 2004) e o registro sedimentar (Hauteriviano até o presente) formou-se em três fases evolutivas (Figura 2) - Rifte e Transicional (Seção Pré-Sal) e Drifte (Seção Pós-Sal).

A fase Rifte (Hauteriviano ao Aptiano) é composta por rochas vulcânicas, conglomerados, arenitos e pelitos (Formações Camboriú, Piçarras e Formação Itapema). A fase transicional (Aptiano ao Albiano) é composta por conglomerados, arenitos, pelitos e carbonatos (Formação Barra Velha) recobertos por evaporitos (Formação Ariri - Camada de Sal).

As fases Rifte e Transicional compõem a Seção Pré-Sal. A fase Drifte (Albiano ao presente), cujo registro litológico compõe a Seção Pós-Sal, é composta de conglomerados, arenitos e pelitos (Formação Florianópolis), carbonatos e pelitos (Formações Guarujá e Itanhaém). Acima deles, ocorrem arenitos e conglomerados proximais (Formações Santos, Juréia e Ponta Aguda), pelitos e margas distais (Formações Itajaí-Açu e Marambaia) com arenitos intercalados (Membros Ilha-Bela e Maresias) (Moreira et al., 2007).

A área de estudos possui aproximadamente
$1900 \mathrm{~km}^{2}$ e localiza-se a $120 \mathrm{~km}$ da costa do Estado de São Paulo (Figuras 1 e 3). Baixos e altos estruturais bordejados por falhas normais caracterizam a Seção Pré-Sal, por sobre a qual ocorrem domos de sal com centenas de metros de espessura. Importantes falhas da área estão nucleadas no topo do Sal, a exemplo da Falha Principal (FP), um par conjugado de falhas normais com direção geral NE-SW (Figura 4).

A Sequência K90 (Santoniano e ao Campaniano; 86- 9 Ma) é composta pelos arenitos do Membro Ilha-Bela (ReservatórioPrincipal), recobertos por pelitos da Formação Itajaí-Açu (Folhelho-Selo ou Selo), que incluem argilitos, siltitos e folhelhos, sobre os quais ocorrem os sedimentos proximais da Formação Juréia (Figuras 2, 3 e 4).

A K90 apresenta altos estruturais com acumulações de gás nos arenitos do Reservatório Principal seladas pelo FolhelhoSelo. Ao sul da FP destaca-se o Alto Estrutural Principal (AP) onde ocorre a Acumulação Principal, a qual possui $800 \mathrm{~m}$ de espessura de zona de gás e contato Gás-Água (G/A) próximo a -5050 m. No Alto Principal ocorre a Zona de Pressão Anormal Principal da área (ZPA Principal), caracterizada por valores de PP anormalmente elevados, estendendo-se entre o horizonte IMA-1 e a base do Reservatório Principal. As unidades mais jovens do que a Sequência K90 apresentam estruturação suave com caimento geral para SW (Figura 4). 


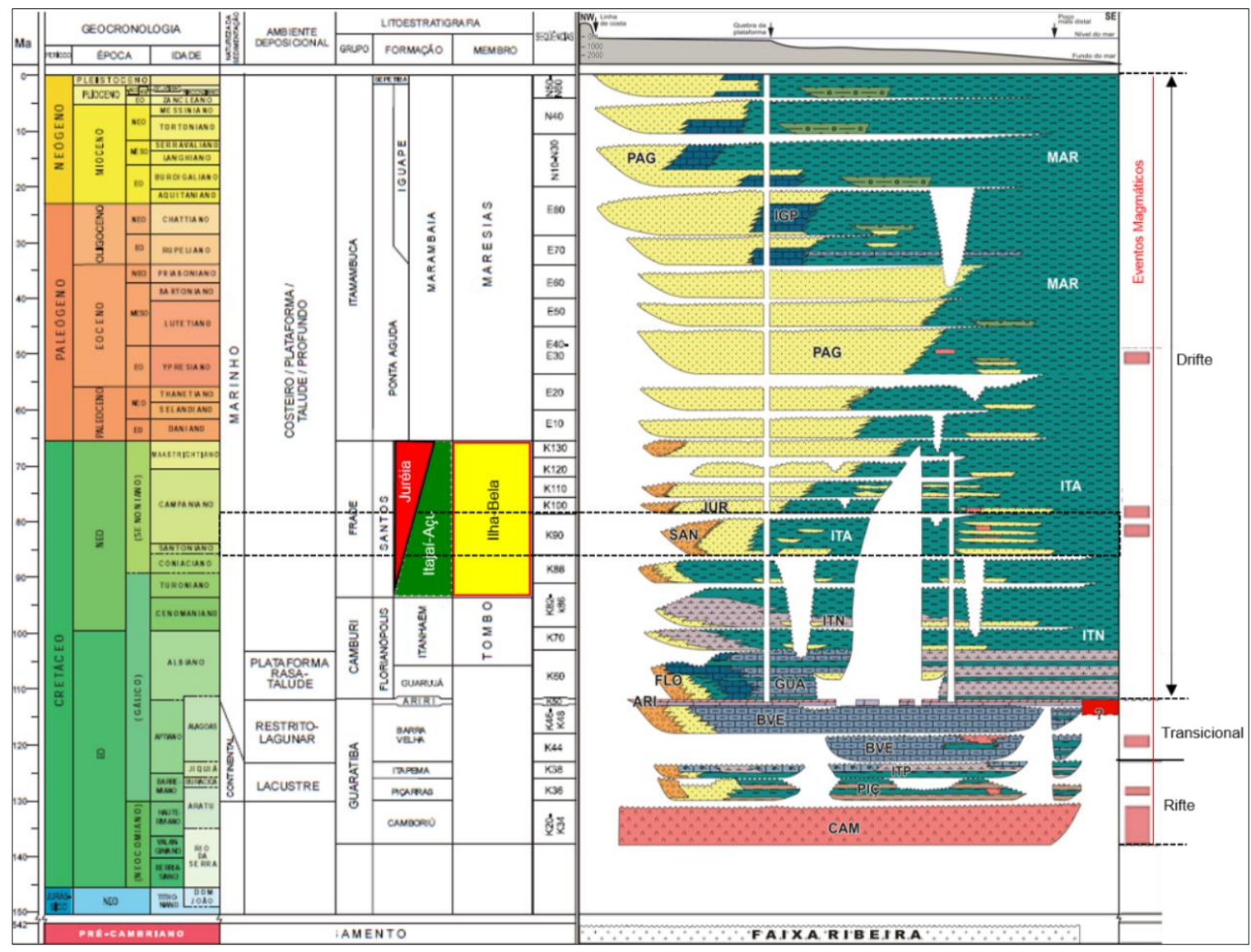

Figura 2 - Carta estratigráfica da Bacia de Santos. Na Sequência K90 (Santoniano ao Campaniano, polígono preto) ocorrem os arenitos do Membro Ilha-Bela (Reservatório Principal) recobertos por pelitos da Formação Itajaí-Açu (Folhelho-Selo) e, no topo, a Formação Juréia. (Modificado de Moreira et al., 2007).

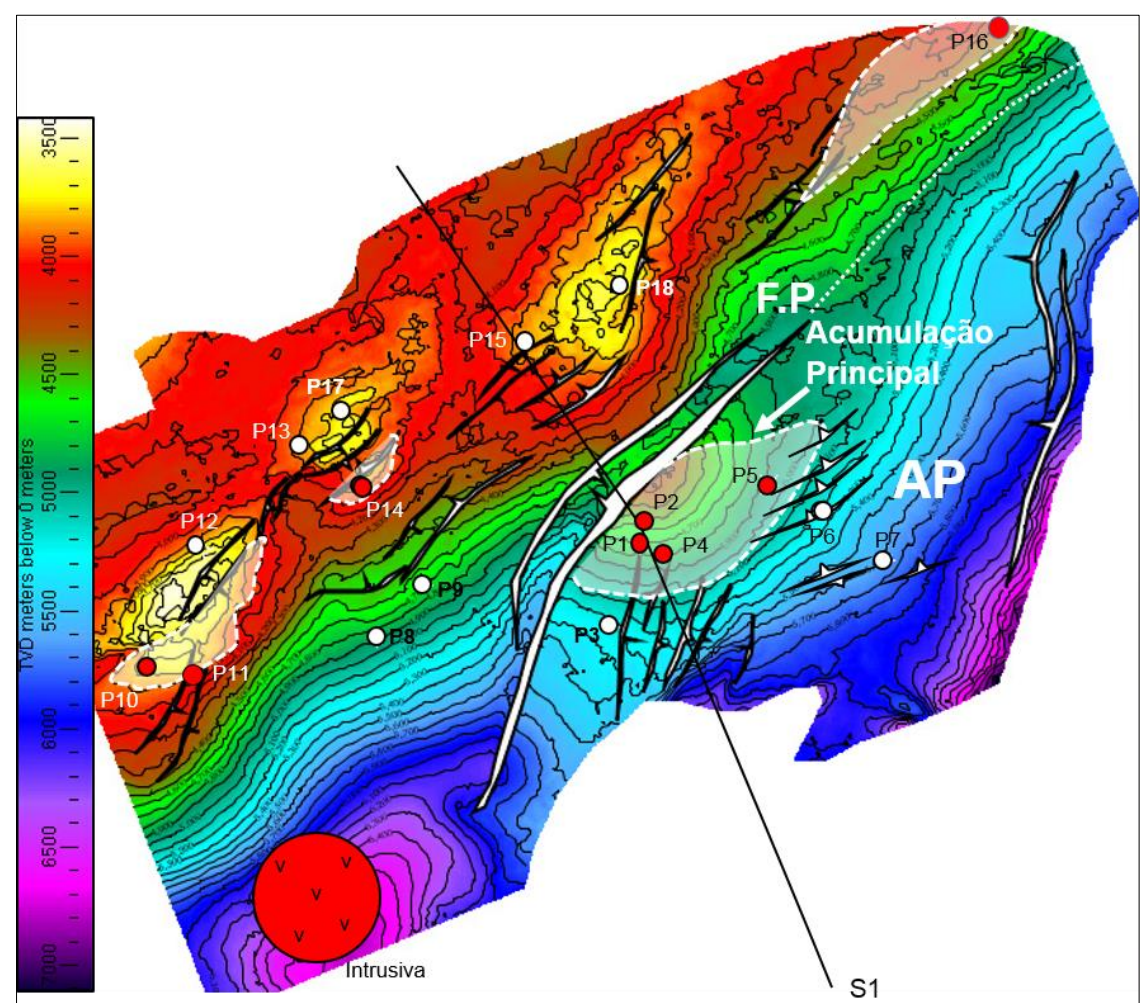

Figura 3 - Mapa estrutural do topo do Reservatório Principal. Contorno de $100 \mathrm{~m}$. Seção apresentada na Figura 4 está destacada (S1). As acumulações de gás estão realçadas em branco. A Falha Principal (FP) secciona a área ao meio. Os poços com gás estão representados em vermelho e os poços com água em branco. No Alto Principal (AP) ocorre a Acumulação Principal (800 m de espessura). A ZPA Principal ocorre no AP (poços P1 ao P7) e a ZPA Secundária ocorre na área do P16. 


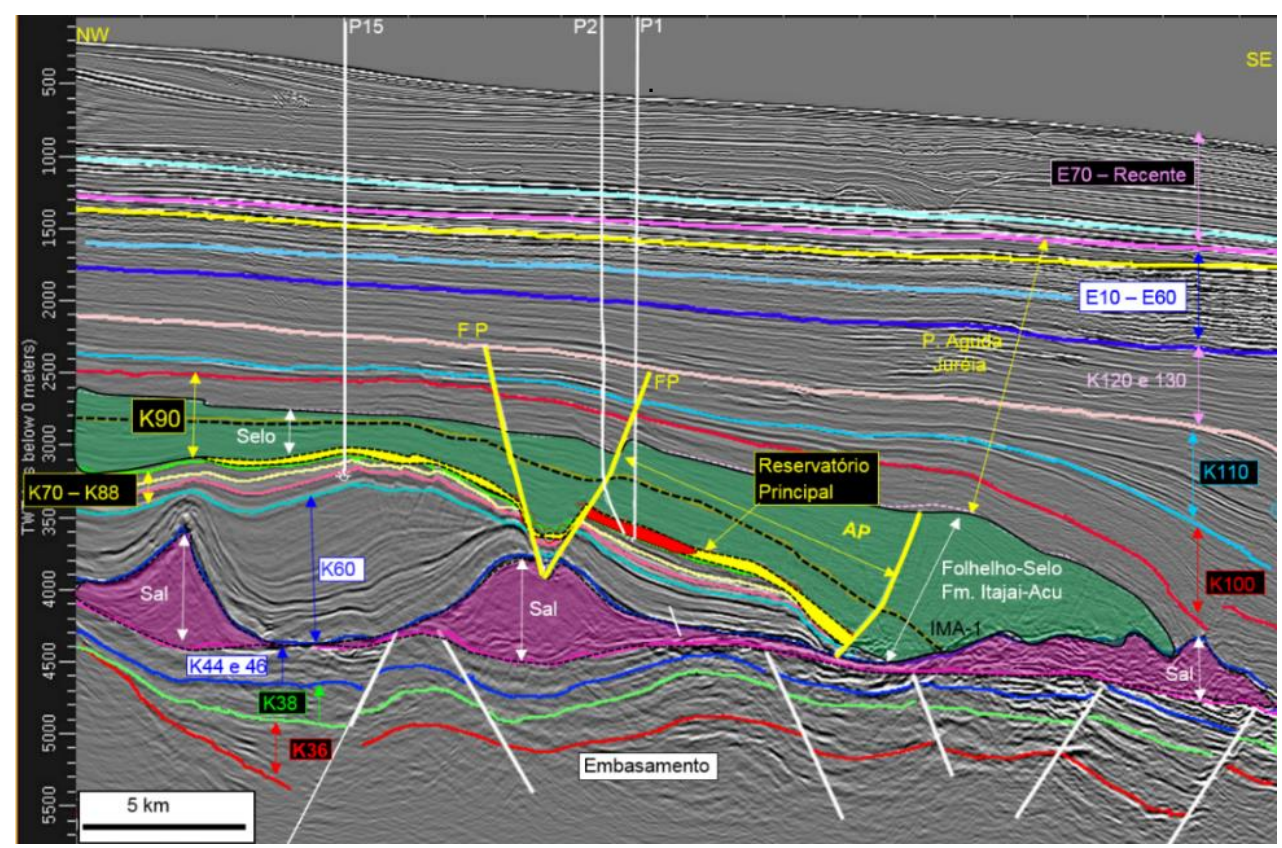

Figura 4 - Seção sísmica entre os poços P15, P2 e P1. Escala vertical em tempo duplo (ms). Ver traçado na Figura 3. A seção Pré-Sal (sequências K36, K38 e K44) apresenta altos e baixos delimitados por falhas normais nucleadas no embasamento. A Sequência K90 inclui o Membro Ilha-Bela (R. Principal), pelitos da Formação Itajaí-Açu (FolhelhoSelo ou Selo) e a Formação Juréia. O Alto Principal (AP) é uma elevação estrutural delimitada pela Falha Principal (FP) e por discordância angular sobre o Sal. O horizonte IMA-1 (Intervalo Menos Argiloso-1) será detalhado nos resultados. Entre o IMA-1 e a base da K90, no AP, ocorre a ZPA Principal. Entre a K100 e E60 (Campaniano ao Eoceno) é discreta a estruturação na área de estudo.

\section{PRESSÕES DE POROS}

A pressão de sobrecarga (PS), ou tensão litostática, é aquela exercida pelo peso dos sedimentos, rochas e fluidos das formações acima de uma certa profundidade (Osborne \& Swarbrick, 1997), podendo ser calculada pela equação:

$$
\text { PS }=\rho \mathrm{s} \cdot \mathrm{g} \cdot \mathrm{Z}
$$

onde PS é a pressão de sobrecarga no ponto de interesse, $\boldsymbol{\rho}$ s é a densidade da coluna litológica (matriz sólida + fluido) acima do ponto de interesse $\left(\mathrm{kg} / \mathrm{m}^{3}\right)$, $\mathbf{g}$ é a aceleração da gravidade $\left(\mathrm{m} / \mathrm{s}^{2}\right)$ e $\mathbf{Z}$ é a profundidade do ponto de interesse $(\mathrm{m})$. O gradiente de pressão de sobrecarga (GPS) é a razão entre PS e Z:

$$
G P S=P S \div Z
$$

A pressão de poros (PP), ou pressão da formação, é aquela exercida na parede dos poros pelo fluido contido neles, em geral a água da formação. Por meio da equação 1, pode-se calcular a PP, bastando substituir $\mathbf{\rho s}$ por $\mathbf{\rho h}$, que é densidade média da água de formação acima do ponto de interesse. $O$ gradiente de pressão de pressão de poros (GPP) é a razão entre $\mathrm{PP}$ e $\mathrm{Z}$ (equação 2).A PP é considerada normal quando é igual àquela exercida por uma coluna de água com a mesma altura da profundidade de interesse. Nesta situação, é denominada de pressão hidrostática (PH) e apresenta um

\section{gradiente de pressão hidrostática (GPH)} (Figura 5).

Admite-se que nesta situação há comunicação hidráulica entre os compartimentos de uma bacia, aliviando-se os eventuais aumentos do GPP pela expulsão de fluidos para o meio adjacente (Domingues, 2008). Quando a PP está acima da PH, ou seja, o GPP é maior do que o GPH, há sobrepressão (Figura 5). Isso decorre de um fluxo ineficiente de fluidos da rocha ao meio adjacente, estabelecendo-se um desequilíbrio do GPP em relação ao GPH regional, como se a rocha constituísse um compartimento isolado do resto da bacia (Swarbrick \& Osborne, 1998), ou seja, uma Zona de Pressão Anormal - ZPA (Picolini, 2017).

Para o desenvolvimento de uma ZPA e sua manutenção ao longo do tempo, é necessário que a permeabilidade da rocha seja baixa o suficiente para retardar as trocas de fluidos com o meio adjacente.

Em geral, as rochas com sobrepressão apresentam permeabilidades iguais ou menores a $10^{-6} \mathrm{mD}$ (Burrus, 1998; Domingues, 2008).

Também é necessário que as falhas existentes no selo estejam estabilizadas, caso contrário haverá dissipação de fluidos e equalização das pressões de poros. 


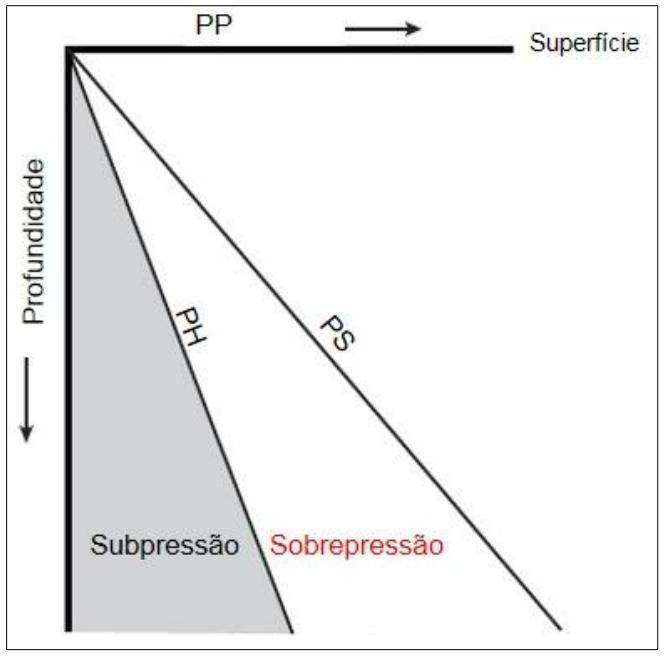

Figura 5 - Gráfico esquemático de pressão de poros (PP) versus profundidade. Observar a variação de pressão hidrostática (PH) e pressão de sobrecarga (PS). A reta PH representa a pressão de uma coluna de água de formação até a profundidade de interesse, sendo seu coeficiente angular o gradiente de pressão hidrostática (GPH). Já a reta de PS representa a tensão de sobrecarga, cuja inclinação é o gradiente de pressão de sobrecarga (GPS). As rochas que apresentam subpressão (campo cinza) possuem PP menor que o esperado para certa profundidade (GPP < GPH), e aquelas com sobrepressão (campo branco), possuem PP maior que o esperado para certa profundidade, (GPH < GPP < GPS). (Modificado Swarbrick \& Osborne, 1998).

Neste sentido, o tempo é um parâmetro importante a ser considerado, pois influencia diretamente a distribuição dos fluidos dentro de uma bacia sedimentar. Outro fator importante é a coexistência de diferentes fluidos nos poros das rochas, a exemplo de gás e água no Reservatório Principal. Saturações intermediárias (Sa entre 40\% e $80 \%$ ) implicam na redução da permeabilidade relativa da água $(\mathrm{ka})$ e do gás $(\mathrm{kg})$ (Figura 6), o que contribui com a manutenção de pressões elevadas, já que reduz a troca de fluidos com o meio externo (Osborne \& Swarbrick, 1998).

A sobrepressão pode surgir em decorrência do esforço compressivo atuante ao redor da rocha, se o fluido absorver parte desse esforço que normalmente seria suportado apenas pelos constituintes sólidos. Se o esforço predominante for o vertical, gerado por altas taxas de sedimentação, pode ocorrer a subcompactação (Figura 7), que é o processo de sobrepressurização mais frequentemente identificado nas bacias, comumente associado a deltas de grandes rios atuais ou pretéritos (Burrus, 1998). Como a expulsão de fluido não acompanha a taxa de esforço vertical, a compactação da rocha se

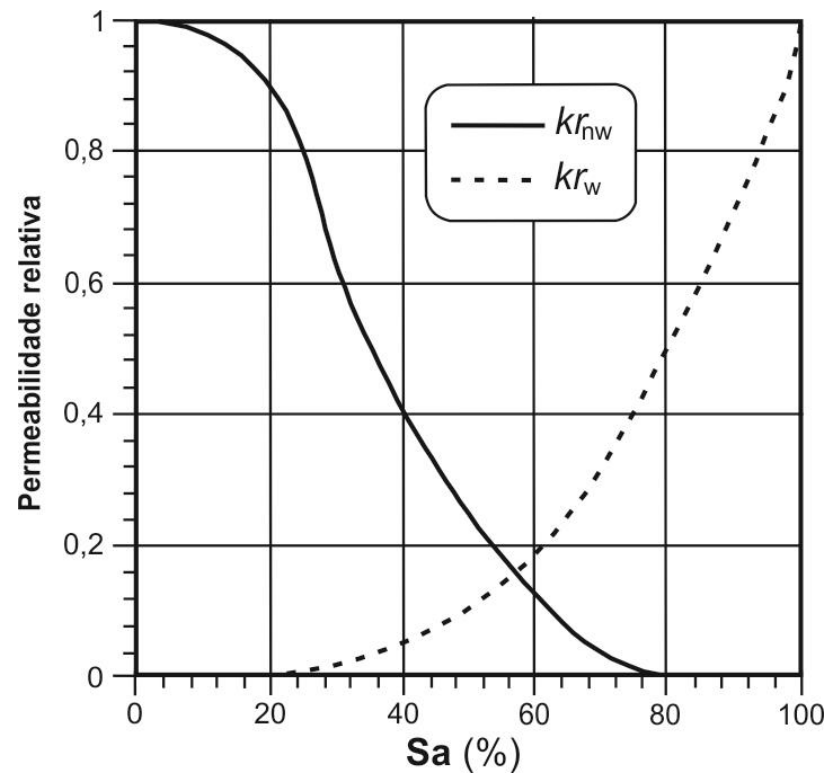

Figura 6 - Saturação de água $\left(S_{\mathrm{a}}\right)$ versus permeabilidade relativa da fase molhante $\left(k r_{\mathrm{w}}\right)$ e não-molhante $\left(k r_{\mathrm{nw}}\right)$. Pode-se considerar fase molhante a água e não-molhante o gás. Assim, $k r_{\mathrm{w}}=k r_{\mathrm{a}}$ e $k r_{\mathrm{nw}}=k r_{\mathrm{g}}$. $\mathrm{O}$ aumento da $\mathrm{S}_{\mathrm{a}}$ implica em maior $k r_{\mathrm{a}}$ e menor $k r_{\mathrm{g}}$. O inverso acontece se houver diminuição de $S_{\mathrm{a}}$ e aumento de $S_{\mathrm{g}}$. Em saturações intermediárias, $\left(\mathrm{S}_{\mathrm{a}} 40 \%\right.$ e $\left.80 \%\right), k r_{\mathrm{a}}$ e $k r_{\mathrm{g}}$ são reduzidas e podem chegar a $1 / 4$ do valor $\left(S_{a}\right.$ próximo a $\left.60 \%\right)$. (Retirado de Rosa et al., 2011).

processa mais lentamente do que o normal, resultando em porosidades anormalmente elevadas (subcompactação). O esforço compressivo que leva à sobrepressão também pode derivar de compressão lateral associada ao tectonismo, halocinese ou argilocinese (Osborne \& Swarbrick, 1997).

A expansão volumétrica gera sobrepressão por aumento do volume original do fluido presente nos poros da rocha. No mecanismo aquathermal, isso decorre de aquecimentos anômalos associados a gradientes geotermais elevados, típicos de áreas com vulcanismo (Swarbrick \& Osborne, 1997).

A transformação mineral gera excesso de fluido por reações entre os constituintes minerais da rocha, sendo a reação mais conhecida a transformação da esmectita em illita (Alnes \& Liburn, 1998).

A expansão volumétrica pode ocorrer na geração de petróleo associada a maturação de intervalos ricos em matéria orgânica (Burrus, 1998).

O movimento do fluido leva à sobrepressurização por adição de fluido proveniente do 


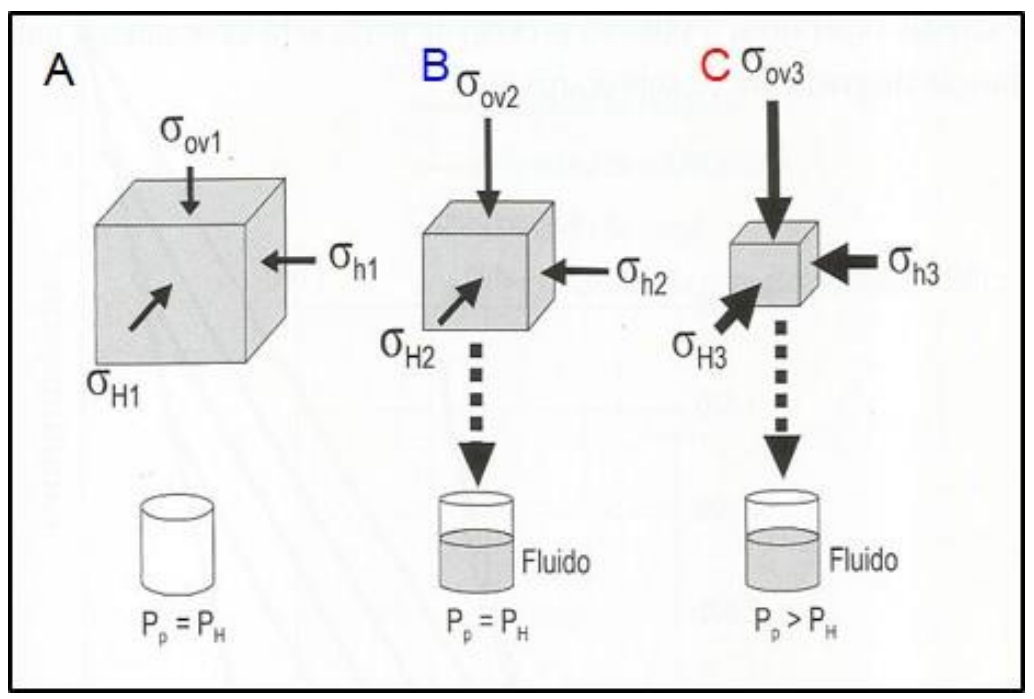

Figura 7 - Representação esquemática do desenvolvimento da subcompactação. Os poros da rocha são representados pelos cubos. A - Os esforços atuantes decorrem da PS e atuam no sentido vertical ( $\sigma$ ov) e horizontal ( $\sigma$ oh). B - Os esforços levam à redução do poro e expulsão de fluido em taxas iguais, mantendo PP igual a PH. C - O aumento do esforço vertical leva a redução de poros em taxa maior do que a expulsão de fluido pode acompanhar, resultando em PP maior que PH (Modificado de Rocha \& Azevedo, 2009).

meio externo (Swarbrick e Osborne, 1998). A Swarbrick, 1997). A Flutuabilidade do Fluido osmose resulta de fluxos por contrastes de leva à formação da zona de óleo e/ou gás, Salinidade entre compartimentos da bacia, resultando em sobrepressurização por que há podendo ocorrer nas vizinhanças de domos de Sal. contraste de densidade do hidrocarboneto com a A altura piezométrica gera acréscimo de pressão água de formação (aquífero), sendo comum nas em relação ao datum potenciométrico, como trapas de petróleo (Rocha \& Azevedo, 2009), a ocorre nas bacias emersas onde a recarga de exemplo das que ocorrem no Reservatório aquífero ocorrem em áreas elevadas (Osborne \& Principal (Figuras 4 e 8).

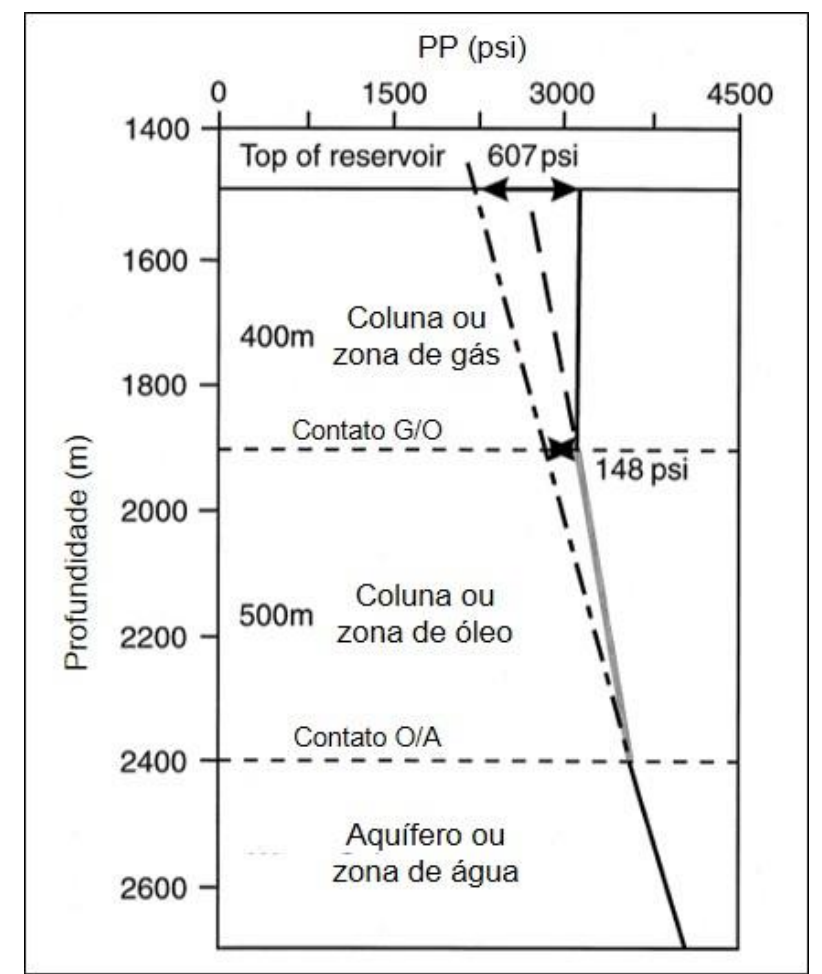

Figura 8 - Efeito da flutuabilidade do fluido para sobre pressurização. A força de empuxo leva à concentração do petróleo acima da água. A diferença de pressão entre a zona de óleo e gás com o aquífero é a sobrepressão. (Modificado de Swarbrick \& Osborne, 1998). 


\section{MATERIAIS E MÉTODOS}

Os modelos de pressão de poros (PP) foram obtidos com o Método de Eaton (1975), que se baseia na relação empírica entre a resposta dos perfis geofísicos de poços e as PPs ao longo da profundidade. Os valores dos perfis seguem uma reta de tendência ao longo da profundidade, ao mesmo tempo em que a compactação das rochas aumenta e sua porosidade diminui, segundo uma Tendência Normal de Compactação (TNC) (Figura 9). Desvios em relação à TNC são identificados nos perfis e podem estar associados a zonas com sobrepressão, sendo possível calcular a pressão de poros através da Equação de Eaton (1975):

$$
\mathrm{PP}=\mathrm{PS}-\left[(\mathrm{PS}-\mathrm{PH}) .\left(\mathrm{V}_{0} \div \mathrm{V}_{\mathrm{n}}\right)^{\mathrm{E}}\right]
$$

onde PP é a pressão de poros, PS é a pressão litostática, PH é a pressão hidrostática, Vo é a velocidade sônica medida no ponto analisado, Vn é o valor da velocidade sônica normal que seria obtida ao longo da TNC e $\mathbf{E}$ é uma constante de calibração em função da área estudada, doravante denominada de Parâmetro de Eaton (Eaton, 1975).

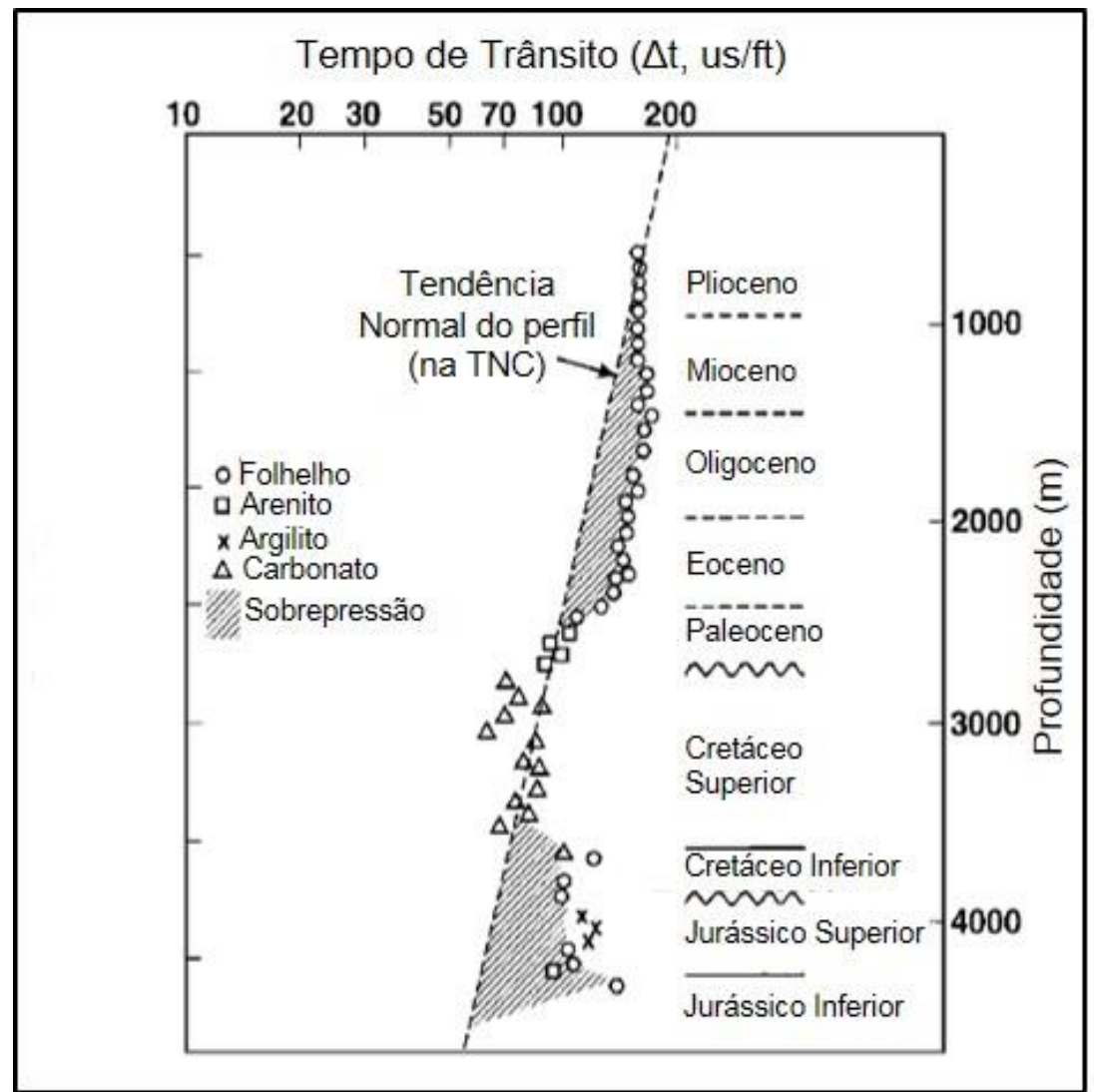

Figura 9 - Tempo de trânsito x profundidade. A variação do tempo de trânsito diante da Tendência Normal de Compactação (TNC) é representada pela reta tracejada. Onde a pressão de poros é normal, o valor dos perfis ajusta-se à reta de tendência normal do perfil. Em zonas com sobrepressão (áreas hachuradas) o tempo de trânsito é maior e os valores se afastam da tendência normal. Desta forma é possível relacionar a resposta dos perfis com a pressão de poros, que é o princípio da modelagem de pressões pelo método de Eaton (1975). Segundo Eaton (1975), este fenômeno está associado ao desequilíbrio de compactação. Segundo Bowers (1995), outros processos podem gerar as zonas sobrepressurizadas e resultar na mesma resposta dos perfis. Exemplo do Gráben Central do Mar do Norte (Modificado de Swarbrick \& Osborne, 1998).

Segundo Eaton (1975) Burrus (1998) e Swarbrick et al. (2002), as zonas alteração dos perfis estão associadas à menor compactação e maior porosidade do que aquela preconizada pela TNC, estando associadas à subcompactação (Figura 7). No entanto, Bowers (1995), Domingues (2008) e Marçal et al. (2012) admitem que a mudança da resposta da velocidade sônica (equação 3) decorre da redução da tensão efetiva, podendo ou não estar associado a subcompactação. Segundo Bowers \& Katsube (2002), a subcompactação afeta a estrutura da rocha como um todo, alterando a resposta dos perfis de rocha total (ex. densidade e neutrão) e transporte (ex. sônico e resistividade). Já a sobrepressurização decor- 
rente da expansão de fluidos e movimentos de fluido, não causa aumento do volume de poros, mas apenas das gargantas de poros, alterando a resposta dos perfis de transporte, mas não interferindo nos perfis de rocha total. Assim, a análise conjunta de diferentes perfis pode indicar qual mecanismo levou a sobrepressão.

\section{Construção dos Modelos}

A modelagem petrofísica foi realizada com o software Interact Petrophysics, de propriedade da Senergy. Os modelos foram calibrados com medidas de pressão obtidas de Testes de Formação, incluindo Pré-Testes (PT), Testes de Formação a Cabo (TFC) e Testes de Formação a Poço Revestido (TFR) (Thomas, 2004). Seções sísmicas e avaliações quantitativas de perfis, disponíveis previamente a esta pesquisa, complementaram as análises.

A pressão de sobrecarga foi calculada pela equação:

$$
\operatorname{PS}(Z)=\int_{Z_{0}}^{Z} \rho b(Z) \cdot g \cdot d Z+P_{o}
$$

onde PS é a pressão de sobrecarga na profundidade $\mathbf{Z}, \mathbf{g}$ é a constante gravitacional, ob é a densidade total da rocha, obtida do perfil de densidade, Po é a pressão em superfície, que no mar é pressão da lâmina d'água (densidade = $\left.1,02 \mathrm{~g} / \mathrm{cm}^{3}\right), \mathbf{Z o}$ é a profundidade inicial e $\mathbf{Z}$ é a profundidade de interesse (Swarbrick \& Osborne, 1998). Nos intervalos sem perfil de densidade, PS foi calculada a partir de valores de referência para a densidade das formações existentes na área de estudo (Picolini, 2017).

A pressão hidrostática foi calculada pela equação:

$$
\mathrm{PH}(\mathrm{Z})=\int_{\mathrm{Z}_{0}}^{\mathrm{Z}} \rho \mathrm{h}(\mathrm{Z}) \cdot \mathrm{g} \cdot \mathrm{dZ}+\mathrm{P}_{\mathrm{o}}
$$

onde PH é a pressão hidrostática em um ponto na profundidade $\mathbf{Z}, \mathbf{g}$ é a constante gravitacional e $\mathbf{\rho h}$ é a densidade do fluido dos poros no ponto de interesse (Swarbrick \& Osborne, 1998). O valor de $\boldsymbol{\rho} \mathbf{h}$ foi definido a partir de amostras de água obtidas em poços da área $\left(\boldsymbol{\rho h}=1,02 \mathrm{~g} / \mathrm{cm}^{3}\right.$ a $1,10 \mathrm{~g} / \mathrm{cm}^{3}$ ), resultando em GPH entre $8,5 \mathrm{ppg}$ e 9,5 ppg. Considerou-se que há sobrepressão quando GPP está acima de 10 ppg, como é o normalmente adotado na perfuração de poços (Granitoff, 2004; Domingues, 2008; Rocha \& Azevedo, 2009; Picolini, 2017).

O valor de Vo (equação 3) foi obtido com o perfil sônico dos poços, enquanto $\mathrm{Vn}$ foi definida a partir da linha de tendência do mesmo perfil, admitida como a TNC de cada poço (Figura 9). A definição da TNC foi feita a partir de rochas pelíticas, mais adequadas à aplicação do método de Eaton (Domingues, 2008). O parâmetro $\mathbf{E}$ (equação 3) fornece uma ideia da sensibilidade da velocidade sônica à sobrepressão, ficando próximo de 3 quando há subcompactação e entre 3 e 5 quando há expansão de fluidos (Bowers, 1995 e Marçal et al., 2012).

O valor da pressão do fluido de perfuração, ou " peso da lama" (PL), foi adotado como indicador de sobrepressão. Em geral PL é mantido acima do valor de PP para impedir o influxo de fluidos provenientes da formação, situação denominada de "kick".

As curvas de PL e GPL foram construídas a partir da interpolação de pesos de lama determinados pontualmente ao longo da perfuração dos poços. Medidas da quantidade de gás, proveniente da formação, também foram usadas como indicativo de zonas sobre pressurizadas, pois nelas ocorrem valores elevados de unidades de gás total (UGT) (Thomas, 2004). Os perfis de Raio-Gama foram empregados para indicativo de litologia e o perfil de caliper indicou trechos com anomalias no diâmetro do poço, nos quais a leitura dos demais perfis é prejudicada, devendo ser desconsiderada para construir os modelos.

\section{RESULTADOS}

As pressões são apresentadas em psi - libras por polegada quadrada (1 psi $\sim 6.895 \mathrm{~Pa})$ e os gradientes em ppg - libras por galão (1 ppg $\left.0,12 \mathrm{~g} / \mathrm{cm}^{3}\right)$, unidades do sistema norteamericano usualmente empregadas na perfuração de poços (Tabelas 1 e 2).

Não foi identificada sobrepressão entre a Sequência K100 e o fundo do mar (Campaniano até o Recente) nos poços analisados (P1, P2, P3, P4, P6, P9, P13 e P15) (Tabela 1). Neste intervalo o maior GPP modelado foi 9,8 ppg (P6 e P9) e o maior GPL foi 10,4 ppg (P2). Também não há sobrepressão na sequência K90 a norte da Falha Principal (FP), já que o maior GPP modelado foi 9,7 ppg (P9 e P13) e o maior GPL foi 11,0 ppg (P9). Os modelos foram calibrados com o Expoente de Eaton $(\mathrm{E})=3$, não foram registrados valores expressivos de gás e não ocorreram problemas operacionais relevantes nas perfurações. 
Tabela 1 - Parâmetros empregados e resultados obtidos na modelagem de pressões entre a Sequência K100 e o fundo do mar (Campaniano - Recente) e na Sequência K90 (Santoniano - Campaniano). Estão relacionados os valores máximos de GPP e GPL, além das medidas de teste de formação (PT e TFR) em ppg. Também estão relacionados o fluido predominante no Membro Ilha-Bela (Reservatório Principal), expoente de Eaton (E) e unidades de gás total (UGT) registradas na perfuração. Observar a proximidade entre os valores modelados para o GPP e as medidas dos testes. Os valores de GPL são pouco superiores aos do GPP, pois o "peso de lama" é empregado para controle de PP. "Baixo UGT" significa valores abaixo de 100 UGT. O intervalo K100 - fundo do mar não possui sobrepressão. A K90 está com condições hidrostáticas (poços P9, P13 e P15). A sul da FP, no Alto Principal, ocorre a ZPA Principal na K90 (poços P1 ao P6, em vermelho).

\begin{tabular}{|c|c|c|c|c|c|c|c|c|c|}
\hline \multirow[b]{2}{*}{ Poço } & \multicolumn{4}{|c|}{ K100 - fundo do mar } & \multicolumn{5}{|c|}{ Sequência K90 (ZPA Principal - poços em vermelho) } \\
\hline & $\begin{array}{l}\text { GPP max. } \\
\text { modelado }\end{array}$ & $\begin{array}{l}\text { PT e } \\
\text { TRF }\end{array}$ & $\begin{array}{l}\text { GPL } \\
\max \end{array}$ & $\mathbf{E}$ & $\begin{array}{l}\text { GPP max. } \\
\text { modelado }\end{array}$ & $\begin{array}{l}\text { PT e } \\
\text { TRF }\end{array}$ & $\begin{array}{l}\text { GPL } \\
\max \end{array}$ & $\begin{array}{c}\text { Mb. Ilha-Bela } \\
\text { (fluido e max. UGT) }\end{array}$ & $\mathbf{E}$ \\
\hline $\mathrm{P} 1$ & 9,5 & -- & 9,5 & 3,0 & 12,5 & 12,5 & 12,1 & Gás (máx. 539 UGT) & 4,4 \\
\hline $\mathrm{P} 2$ & 9,6 & -- & 10,4 & 3,0 & 12,6 & 12,4 & 12,9 & Gás (máx. 700 UGT) & 5,5 \\
\hline P3 & 9,4 & -- & 9,7 & 3,0 & 11,7 & 11,5 & 11,8 & Água (baixo UGT) & 3,2 \\
\hline P4 & 9,6 & -- & 9,5 & 3,0 & 12,2 & 12,2 & 12,5 & Gás (máx. 1021 UGT) & 5,5 \\
\hline P6 & 9,8 & -- & 9,7 & 3,0 & 10,9 & 10,7 & 9,9 & Água (máx. 420 UGT) & 3,5 \\
\hline P9 & 9,8 & -- & 9,7 & 3,0 & 9,7 & 9,4 & 11,0 & Água (máx. 240 UGT) & 3,0 \\
\hline P13 & 9,5 & 9,0 & 10,0 & 3,0 & 9,7 & 9,3 & 10,2 & Água (baixo UGT) & 3,0 \\
\hline P15 & 9,5 & -- & 10,2 & 3,0 & 9,6 & 9,3 & 10,3 & Água (máx. 207 UGT) & 3,0 \\
\hline
\end{tabular}

Tabela 2 - Parâmetros empregados e resultados obtidos na modelagem de pressões entre as Sequências K82-86 e K88 (Cenomaniano ao Coniaciano). O significado dos parâmetros relacionados é o mesmo da tabela 1. Os poços P6 e P13 apresentaram condições hidrostáticas. No P3 foi identificada a ZPA-2a e no P4 a ZPA-2b (em vermelho).

\begin{tabular}{c|c|c|c|c|c}
\hline & \multicolumn{5}{|c}{ Sequências K82 e K88 (ZPA-2a e ZPA-2b) } \\
\hline Poço & $\begin{array}{c}\text { GPP max. } \\
\text { modelado }\end{array}$ & $\begin{array}{c}\text { PT } \\
\text { TRF }\end{array}$ & $\begin{array}{c}\text { GPL } \\
\mathbf{m a x}\end{array}$ & $\begin{array}{c}\text { Mb. Ilha-Bela } \\
\text { (fluido e UGT) }\end{array}$ & E \\
\hline P3 & $\begin{array}{c}12,5 \\
\text { (ZPA-2a) }\end{array}$ & 12,1 & 11,7 & $\begin{array}{c}\text { Gás } \\
\text { (1260 UGT) }\end{array}$ & 4,2 \\
\hline P4 & $\begin{array}{c}12,1 \\
\text { (ZPA-2b) }\end{array}$ & -- & 12,4 & $\begin{array}{c}\text { Água } \\
\text { (baixo UGT) }\end{array}$ & 3,0 \\
\hline
\end{tabular}

A sul da FP, na Sequência K90, foi identificada a ZPA Principal nos poços P1, P2, P3, P4 e P6 (Tabela 1 e Figuras 10 e 11), abrangendo parte do Folhelho-Selo e todo o Reservatório Principal. As pressões anormais iniciam-se próximo ao Intervalo de Menor Argilosidade - 1 (IMA-1), com uma zona de transição (ZT), onde ocorre aumento progressivo do GPP. Abaixo da ZT, próximo ao IMA-2, ocorre uma zona franca de pressão (ZF), marcada pelos maiores valores de GPP. O GPP modelado atingiu 12,6 ppg (P2), o GPL chegou a 12,9 ppg (P2) e o parâmetro E variou entre 3,2 (P3) e 5,5 (P2 e P4). Há aumento do perfil sônico e diminuição da resistividade, que só aumenta no IMA-1, IMA-2 e no Reservatório Principal, em função da litologia ou ocorrência de gás. A densidade, o neutrão e o raio-gama não sofrem influência das PPs, variando apenas em função da litologia. As medidas de gás chegaram a 1021 UGT na zona de gás (P4) e 420 UGT na zona de água (P6), Kicks, prisões de coluna e ganhos de ângulo estão associados a sobrepressão (Rocha \& Azevedo, 2009).

As sequências K82-86 e K88 (Cenomaniano ao Coniaciano) estão em condições hidrostáticas nos todo os poços analisados, exceto no P3 e P4 (Tabela 2). No P3 foi identificada uma ZPA-2a, onde o GPP máximo ficou em 12,3 ppg, o GPL máximo empregado foi $11,7 \mathrm{ppg}$, ocorrendo até 1260 UGT próximo ao Membro Ilha-Bela-2 (com gás), sendo utilizado $\mathrm{E}=4,2$ (Tabela $2 \mathrm{e}$ Figura 11). No poço P4 foi identificada a ZPA2b, marcada por GPP máximo de 12,1 ppg e o GPL máximo 12,4 ppg, próximo ao Membro Ilha-Bela (com água), sendo utilizado E=3 (Tabela 2).

A identificação dos compartimentos de pressão existentes na Sequência K90 foi realizada com base nas medidas de pressão 
obtidas nos testes de formação (Figura 12).

Para isso, foram definidas retas de tendência de PP x profundidade para o gás (RTg) e água
(RTa) com base nas densidades de fluidos amostrados (gás $\sim 0,3 \mathrm{~g} / \mathrm{cm}^{3}$ e a água 1,10 $\left.\mathrm{g} / \mathrm{cm}^{3}\right)$.

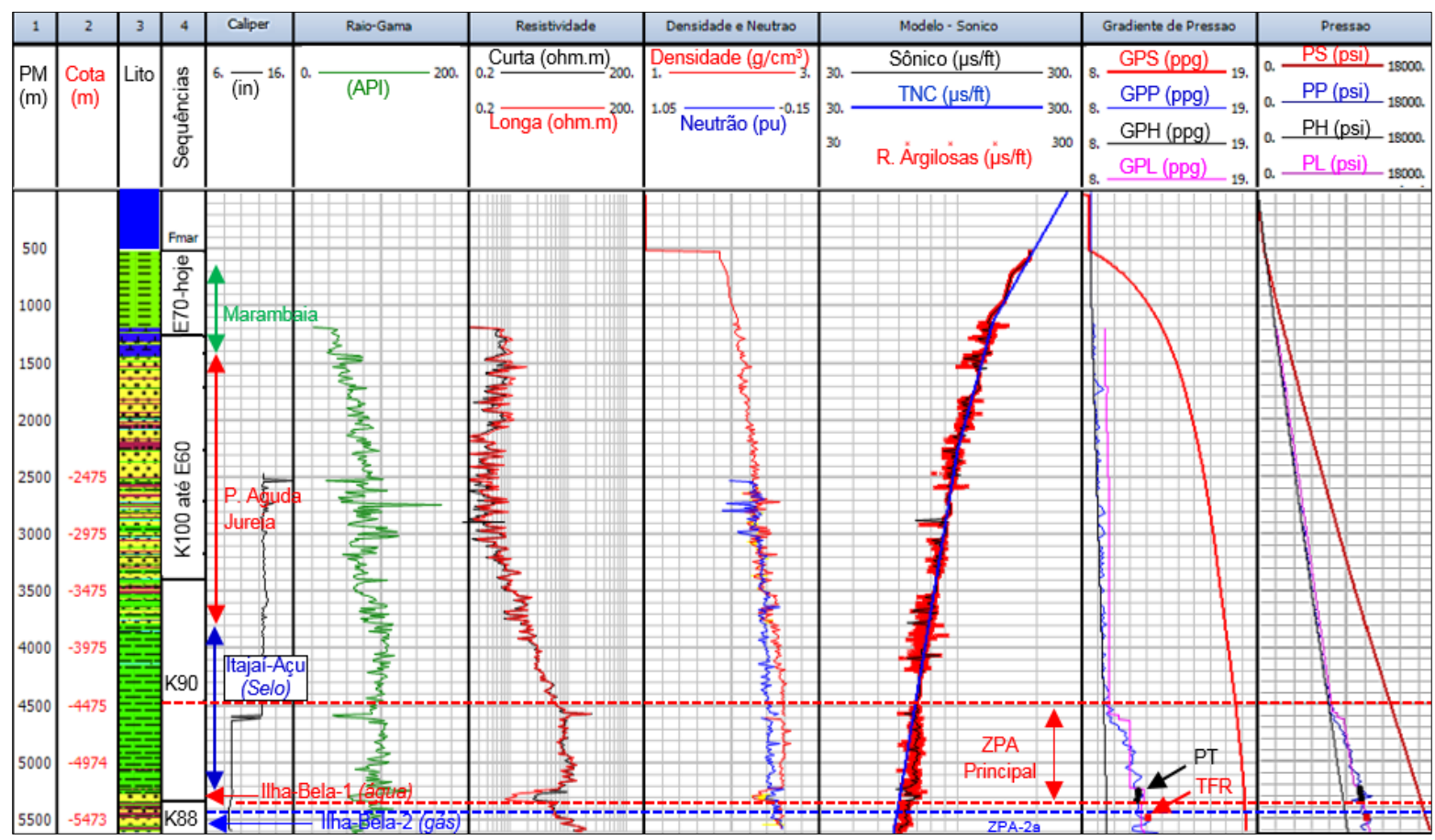

Figura 10 - Perfis do poço P3. Sequência K100 ao fundo do mar está em condição hidrostática. PP está próxima de PH, GPP próximo de GPH, GPP máximo é 9,4 ppg e GPL máximo é 9,7 ppg. Na sequência K90 está a ZPA Principal (4500 $\mathrm{m}-5370 \mathrm{~m})$, conforme detalhado na Figura 10. Na sequência K88 está a ZPA-2a $(5440 \mathrm{~m}-5550 \mathrm{~m})$. Os valores do perfil sônico nos intervalos com caliper irregular, exemplo $2500 \mathrm{~m}$ a $2600 \mathrm{~m}$, foram desconsiderados do modelo.

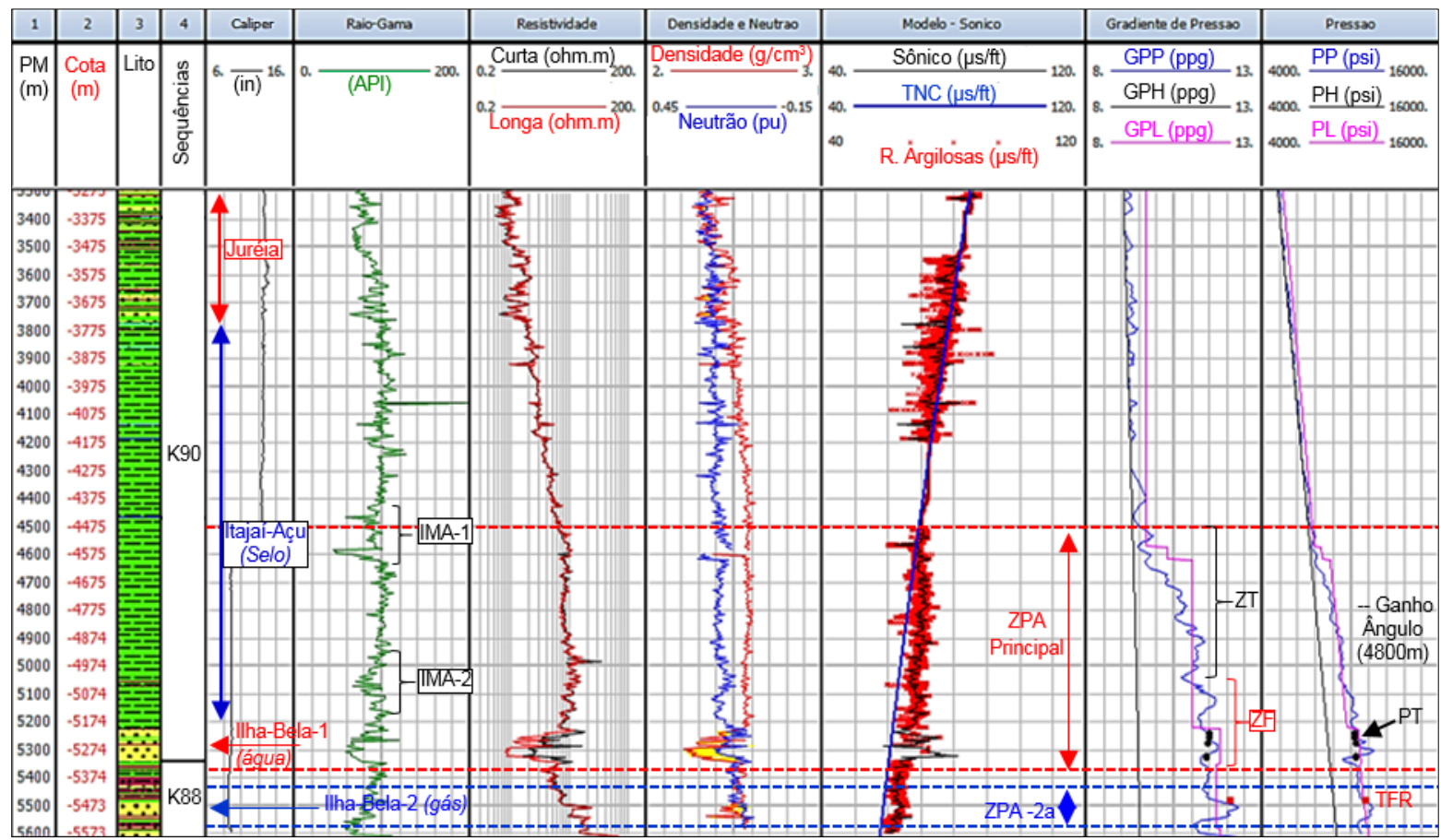

Figura 11 - Perfis do poço P3 a partir de $3300 \mathrm{~m}$. A ZPA Principal é composta por ZT (4500 m - $5050 \mathrm{~m}$ ) e ZF (5050 $\mathrm{m}-5370 \mathrm{~m}$ ). Inicia-se abaixo do IMA-1, engloba parte do Folhelho-Selo e todo o Reservatório Principal (Membro Ilha-Bela-1). O GPP modelado máximo foi 11,7 ppg e o maior GPL 11,8 ppg. Na ZPA Principal há aumento do sônico em relação à TNC e diminuição da resistividade, exceto no Intervalo de Menor Argilosidade - 1 (IMA-1) e no IMA-2, onde aumenta por causa da variação litológica. A densidade, o neutrão e o raio-gama variam por causa da litologia, e são independentes das PPs. Houve ganho de ângulo durante a perfuração (4800 m). A ZPA-2a ocorre na K88, englobando pelitos da Formação Itajaí-Açu e arenitos do Membro Ilha-Bela-2 (5440 m - 5550 m, GPP até 12,3 ppg, GPL até 11,7 ppg). Observar a excelente calibração entre as curvas modeladas e os dados medidos nos testes de formação (PT e TFR). 


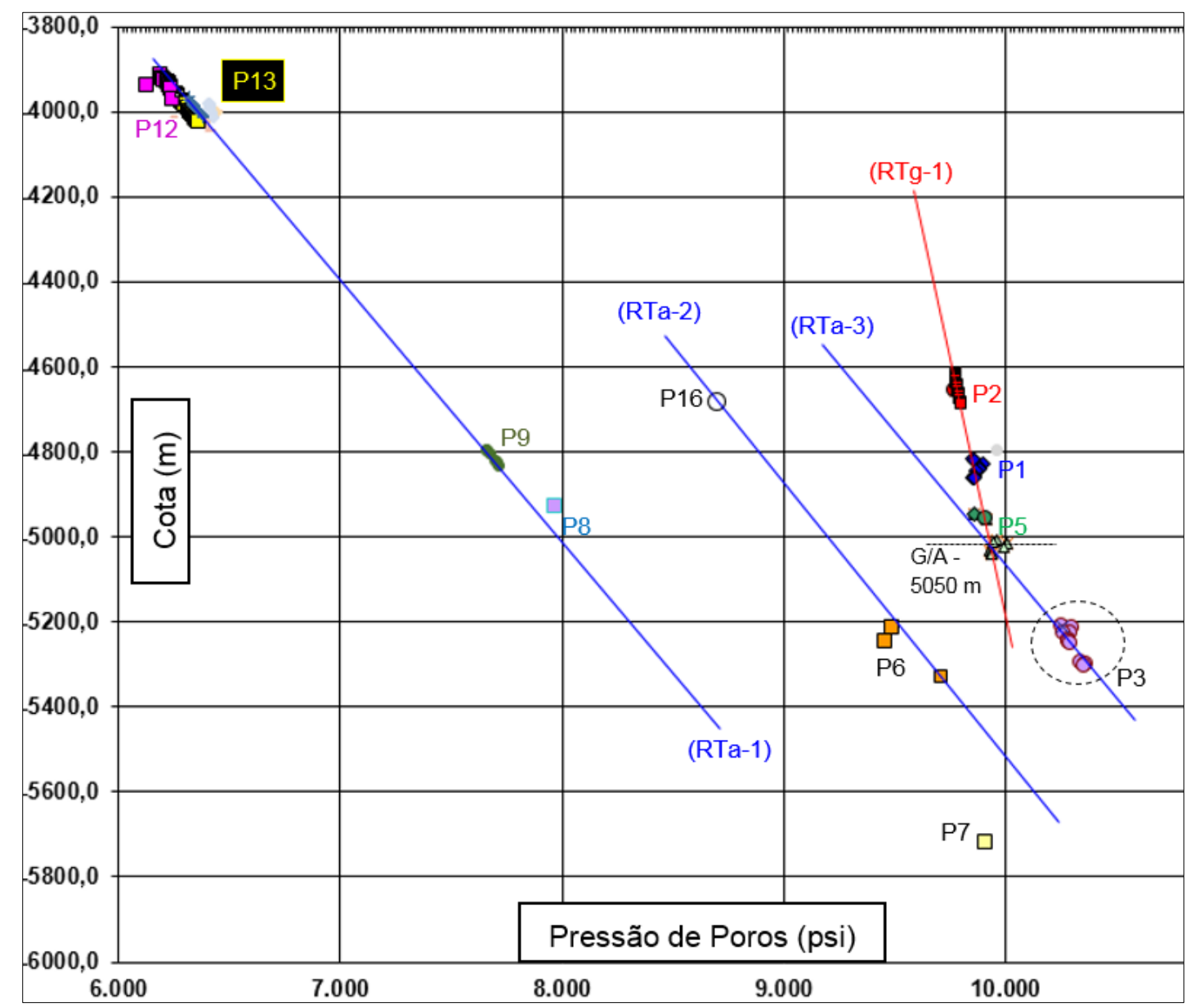

Figura 12 - Pressão poros x cota com os valores de pressão obtidas por PT e TFR realizados na Sequência K90. A inclinação das retas de tendência de água (RTa-1, RTa-2, RTa-3) e gás (RTg-1) foi definida a partir das densidades de fluidos coletados nos poços. A RTa-1 está ajustada ao GPH regional (GPP medido = 9,1 ppg a 9,5 ppg). A RTa-2 está ajustada ao P16 (GPP medido = 10,9 ppg, ZPA secundária) e a RTa-3 está ajustada ao P3, (GPP medido = 11,5 ppg no aquífero da Acumulação Principal). A RTg-1 é a reta ao P1, P2 e P5 no Ilha-Bela-1 (GPP medido = 12 ppg a 12,6 ppg, na zona de gás Acumulação Principal). Observar que na zona de gás da Acumulação Principal, o GPP medido ficou até 1 ppg maior que no aquífero. O contato G/A ficou em -5050 m (cruzamento de RTa3 com RTg1), determinando uma zona de gás com $800 \mathrm{~m}$ de espessura.

A RTa-1 é a reta ajustada às PPs medidas no P8, P9, P12, P13 e P15, onde o GPP é hidrostático. A RTa-2 é a reta ajustada à PP do P16, onde ocorre uma ZPA secundária na K90 $($ GPP medido $=10,9$ ppg $)$. A RTa-3 é a reta de tendência ajustada a PP medida no P3 (GPP = 11,5 ppg), dentro da ZPA Principal (Figura 12).
A RTg-1 é a reta ajustada aos dados de PP dos poços P1, P2, P4 e P5 (Acumulação Principal, GPP entre 12,0 ppg e 12,6 ppg, dentro da ZPA Principal). Sua intersecção com RTa-3 estabeleceu um contato próximo a $-5050 \mathrm{~m}$, o que significa que a zona de gás possui cerca de $800 \mathrm{~m}$ de espessura (Figuras 12 e 13).

\section{DISCUSSÃO DOS RESULTADOS}

Os resultados mostraram que a ZPA Principal está restrita ao Alto Principal e inclui a zona de gás e o aquífero da Acumulação Principal, sendo delimitada, a norte e oeste, pela Falha Principal, a nordeste, pelo fechamento estratigráfico estabelecido pela zona de não-deposição (ND) que retém o gás e, a sul e oeste, pela extinção da K90 contra o Sal (Figuras 12 e 13). Em termos estratigráficos, ela ocorre entre o IMA-1 e a base do
Reservatório Principal (Figuras 10 e 11).

O comportamento dos perfis de rocha total (densidade e neutrão) e os parâmetros de $\mathrm{E}$ empregados na ZPA Principal $(\mathrm{E}=3$ a 5) indicam que não há variação da porosidade total e, assim, a subcompactação não deve ter atuado na K90. A resposta dos perfis de transmissão (sônico e resistividade) e o valor do E indicam que há aumento do tamanho das gargantas de poros associado com a expansão volumétrica do 
fluido presente nos poros (Bowers \& Katsube, 2002; Domingues, 2008; Marçal et al., 2012). Picolini (2017) considerou que os mecanismos de expansão volumétrica não atuaram de forma relevante, já que não há relação entre as pressões anormais e a evolução tectonossedimentar da área de estudo, descartando a atuação dos mecanismos aquathermal, transformação esmectita - illita e geração de hidrocarboneto.

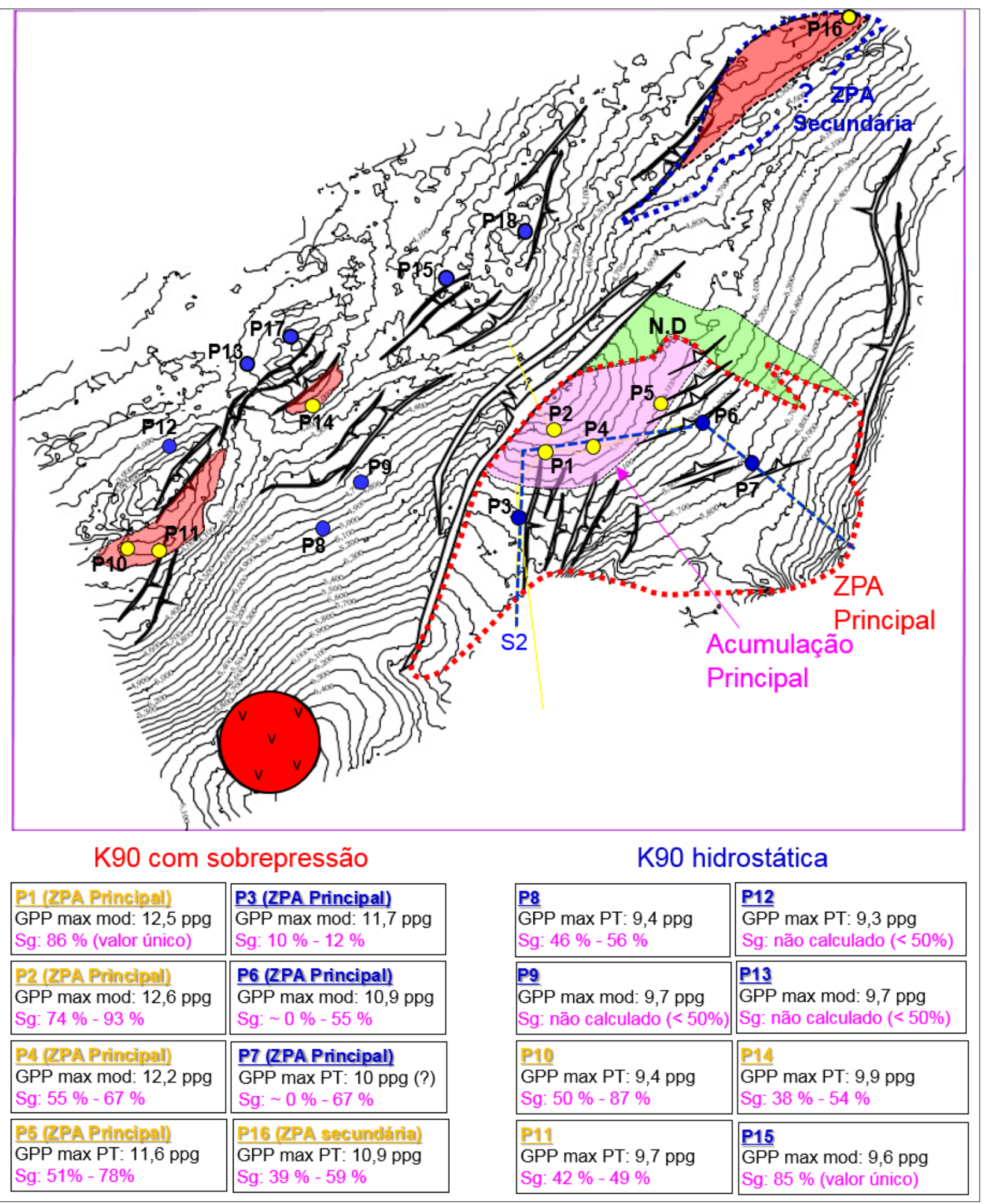

Figura 13 - Mapa estrutural do topo do Reservatório Principal. Contorno de $100 \mathrm{~m}$. Poços com gás estão em amarelo e poços com água em azul. Os valores de GPP máximos modelados e as medidas de PT estão relacionadas abaixo do mapa, juntamente com medidas de saturações de gás $(\mathrm{Sg})$. Os poços da zona de gás apresentam valores de $\mathrm{Sg}$ média > $50 \%$ e os poços do aquífero apresentam Sg média < $50 \%$. Seção apresentada na figura14 está destacada (S2). A zona de não-deposição de reservatórios (ND) é o limite estratigráfico da Acumulação Principal a NE. Observar que a Acumulação Principal tem $800 \mathrm{~m}$ de espessura de zona de gás. 


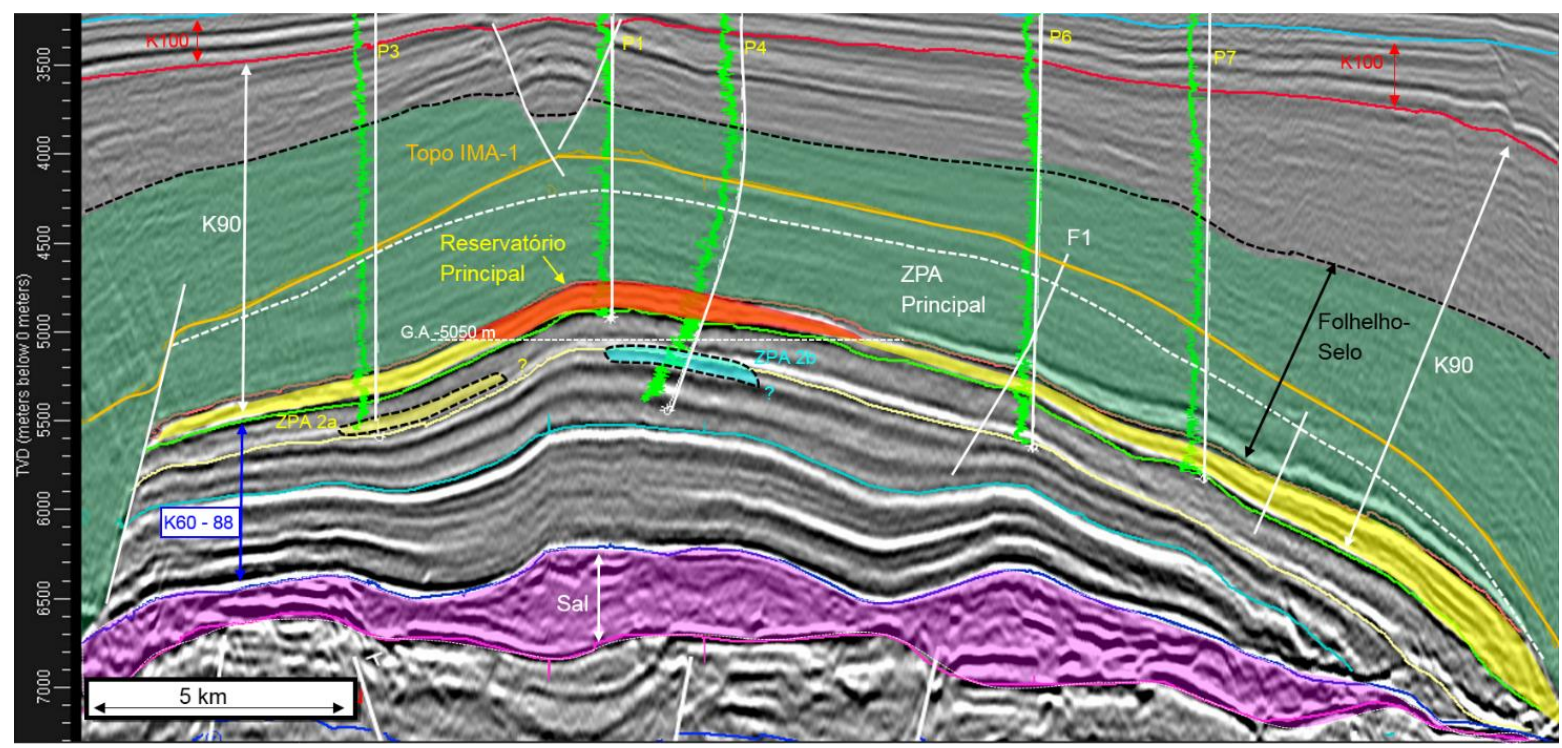

Figura 14 - Linha sísmica em profundidade entre os poços P3, P1, P4, P6 e P7. Escala vertical em metros. Ver traçado na Figura 12. A ZPA Principal ocorre entre o IMA-1 e a base da Sequência K90, englobando parte do Folhelho-Selo e o Reservatório Principal. A ZPA-2a (P3) e ZPA-2b (P4) estão representadas, sendo seus limites espaciais desconhecidos.

É provável, então, que a expansão volumétrica do fluido, indicada nos modelos de pressão, seja consequência da ocorrência de gás no Reservatório Principal e no Folhelho-Selo.

$O$ gás foi $\mathrm{o}$ elemento decisivo para o desenvolvimento e manutenção da ZPA Principal, elevando o GPP na zona de gás, em relação ao aquífero, como evidenciado pelo aumento do GPP em direção ao ápice do Alto Principal concomitante com o aumento da saturação de gás (Figura 13).

Este aumento chega a quase $\sim 1 \mathrm{ppg}$, pois o GPP atinge até 12,6 ppg (P2) na zona de gás e 11,7 ppg (P3) no aquífero. Reforça esta afirmação o fato dos dados de testes de formação se alinharem à reta de tendência $\mathrm{PP}$ versus profundidade do gás (RTg-1), o que evidencia que o aumento do GPP segue a tendência definida pela densidade média do gás (Figura 12).

Outra contribuição do gás para a sobrepressão resultou da sua coexistência com a água, pois a consequente redução das permeabilidades relativas no Folhelho-Selo e no Reservatório Principal teria retardando o fluxo de fluidos ao meio adjacente (Figura 6). Picolini (2017) considerou que permeabilidades relativas de gás e água, estabelecidas em condição de $\mathrm{Sa}$ e $\mathrm{Sg}$ intermediárias (Figura 13) seriam suficientes para manter sobrepressões compatíveis com o aquífero da ZPA Principal (11,5 ppg).

Barreiras de permeabilidade internas ao Folhelho-Selo, compostas por litologias menos permeáveis e talvez mais cimentadas, devem ter amplificado a retenção de fluidos e contribuído com o desenvolvimento e manutenção dos GPPs elevados ao longo do tempo. Isso poderia ser exemplificado pelo IMA-1, IMA-2 e a zona ND que delimita a ZPA Principal a NE (Figuras $13 \mathrm{e}$ 14). Falhas selantes também reduziram o fluxo de fluidos, como exemplificado pela FP.

Ressalta-se, por fim, que fluidos sobrepressurizados poderiam ter migrado para a Acumulação Principal a partir de níveis inferiores à K90 por meio de falhas ou camadas carreadoras, a exemplo daqueles onde ocorrem a ZPA-2a e ZPA-2b, ampliando o GPP (Swarbrick \& Osborne, 1998; Rocha \& Azevedo, 2009). Porém esse é um ponto a ser melhor analisado por trabalhos futuros.

\section{CONCLUSÕES}

Não há sobrepressão entre a Sequência K100 e o fundo do mar na área de estudo. A K90 apresenta condições hidrostáticas a norte da FP (poços P8 ao P18), exceto na área do P16, onde ocorre a ZPA secundária. A sul da FP ocorre a ZPA Principal, delimitada pela Falha Principal e a zona não deposição ND. Ela abrange parte do
Folhelho-Selo e todo o Reservatório Principal, incluindo a zona de gás e o aquífero. O IMA-1 e IMA-2 atuaram como barreiras de permeabilidade, limitando o topo da ZT e ZF, respectivamente, o que significa que há controle estratigráfico na equalização das pressões de poros. O gás é o principal elemento causador 
das pressões anormais na ZPA Principal, elevando as pressões de porosa na zona de gás e contribuindo com a redução das permeabilidades relativas dos fluidos no Folhelho-Selo e Reservatório Principal. Intervalos menos permeáveis, a exemplo do IMA-1 e IMA-2, ou da zona de não deposição de reservatórios (ND), atuaram como barreiras de permeabilidade, amplificado ainda mais a retenção de fluídos, contribuindo com a manutenção do GPP elevado. Fluidos sobrepressurizados podem ter migrado de níveis inferiores, a exemplo da ZPA-2a e ZPA-2b, contribuído com o aumento do GPP da ZPA Principal.

\section{AGRADECIMENTOS}

Os autores agradecem a Petrobras (Petróleo Brasileiro S.A.) pela liberação dos dados e fornecimento de recursos necessários a pesquisa e ao LEBAC (Laboratório de estudos de bacias) da UNESP pelo apoio na realização da pesquisa. Agradem aos colegas Antônio Celso Guirro, Luiz Manoel Alves Marçal, Marcelo Brasil Silka, Roman Hotzel Escardó, pelas discussões técnicas relevantes e ajuda na obtenção dos resultados, bem como à Maria Rita Caetano Chang pela revisão final.

\section{REFERÊNCIAS}

ALNES, J.R. \& LILBURN, R.A. Mechanisms for generating overpressure in sedimentary basins: a reevaluation: a discussion. AAPG Bulletin, v. 82, p. 2266-2269, 1998.

BOWERS, G.L. Pore pressure estimation from velocity data: accounting for overpressure mechanisms besides undercompaction. SPE Drilling and Completion, v. 10, n. 2, p. 89-95, 1995.

BOWERS, G.L. \& KATSUBE, T.J. The role of shale pore structure on the sensitivity of wire-line logs to overpressure. In: HUFFMAN, A.R. \& BOWERS, G.L. (Eds). Pressures regimes in sedimentary basins and their prediction. Tulsa: AAPG, p. 43-60, 2002

BURRUS, J. Overpressure models for clastic rocks, their relation to hydrocarbon expulsion: a critical reevaluation. In: Law, B.E., Ulmishek, G.F., Slavin, V.I. (Ed.). Abnormal pressures in hydrocarbon environments. Tulsa: AAPG, $p$. 35-63, 1998.

CHANG, H.K.; KOWSMANN, R.O.; FIGUEIREDO, A.M.F.; BENDER, A.A. Tectonics and stratigraphy of the East Brazil Rift System: an Overview. Tectonophysics, v. 213, p. 97-138, 1992.

COBBOLD, P.R.; MEISLING, K.E.; MOUNT, V.S. Reactivation of an obliquely rifted margin, Campos and Santos basins, southeastern Brazil. AAPG Bulletin, v. 85, n. 11, p. 1925-1944, 2001.

DOMINGUES, M. Estudo comparativo de métodos de estimativa de pressão de poros em poços da Bacia do Espirito Santo. Rio de Janeiro. Dissertação (Mestrado em Ciências em Engenharia Civil) - Coordenação dos Programas de Pós-Graduação em Engenharia, Universidade Federal do Rio de Janeiro. 99 p. 2008.

EATON, B.A. The equation for geopressure prediction from well logs. In: Annual Fall Meeting, 50, 1975, Dallas. In: Proceeding...Dallas: Society of Petroleum Engineering, 1975, $11 \mathrm{p}$.

GRANITOFF, W. Controls on overpressure development, Santos Basin, Brazil. Londres, 2004. Dissertação (Master of Science) - University of London.

HEILBRON. M.; PEDROSA-SOARES, A.C.; NETO, M.C.C.; SILVA, L.C.; TROUW, R.A.J.; JANASI, V.A. Província Mantiqueira. In: MANTESSO NETO, V.; BARTORELLI, A.; CARNEIRO, C.D.R.; BRITO-NEVES, B.B. (Org.). Geologia do continente Sul-Americano: evolução da obra de Fernando Flávio Marques de Almeida. São Paulo: Beca, p. 203-265,2004.

LAW, B.E. \& SPENCER, C.W. Abnormal pressures in hydrocarbon environments. In: Law, B.E., Ulmishek, G.F.,
Slavin, V.I. (Eds). Abnormal pressures in hydrocarbon environments. Tulsa: AAPG, p. 1-11, 1998.

MARÇAL, L.M.A.; CARVALHO, J.G.; LIMA, F.M.; DOMINGUES, M. Geopressões: metodologias de trabalho do E\&P-EXP. In: Seminário Técnico de Operações Geológicas, 2012, Rio de Janeiro. In: Atas...Rio de Janeiro: Petrobras, 2012, 9 p.

MOREIRA, J.L.P.; MADEIRA, C.V.; GIL, J.A.; MACHADO, M.A.P. Bacia de Santos. Boletim de Geociências da Petrobras, v. 15, n. 2, p.531-549, 2007.

OSBORNE, M.J. \& SWARBRICK, R.E. Mechanisms for generating overpressure in sedimentary basins: A Reevaluation. AAPG Bulletin, v. 81, n. 6, p. 1023-1041, 1997.

PECTEN-MARATHON-SHELL. 1-SPS-11-SPS Santos Basin, Brazil, final well report. Rio de Janeiro: PECTENMARATHON-SHELL, 89 p, 1978.

PICOLINI, J.P. Estudo das pressões de poros numa área central da Bacia de Santos. Dissertação (Mestrado em Geociências e Meio-Ambiente) - Instituto de Geociências e Ciências Exatas, Universidade Estadual Paulista Júlio de Mesquita Filho 162 p. 2017.

ROCHA, L.A.S. \& AZEVEDO, C.T. Projeto de poços de petróleo. Geopressões e colunas de revestimentos. 2 ed. Rio de Janeiro: Interciência, 561 p, 2009.

ROSA, A.; CARVALHO, R.S.; XAVIER, J.A.D. Engenharia de reservatórios de petróleo. Rio de Janeiro: Interciência, 832p, 2011.

SWARBRICK, R.E. \& OSBORNE, M.J. Mechanisms that generate abnormal pressures: an overview. Law, B.E., Ulmishek, G.F., Slavin, V.I. (Ed.). In: LAW, B.E.; ULMISHEK, G.F.; SLAVIN, V.I. (Eds). Abnormal pressures in hydrocarbon environments. Tulsa: AAPG, p. 13-34, 1998.

SWARBRICK, R.E.; OSBORNE, M.J.; YARDLEY, G.S. Comparison of overpressure magnitude resulting from the main generating mechanisms. In: Huffman, A. R.; Bowers, G.L. (Eds). Pressures regimes in sedimentary basins and their prediction. Tulsa: AAPG, p. 1-12, 2002.

THOMAS, J.E. (Org.). Fundamentos de engenharia de petróleo. 2 ed. Rio de Janeiro: Interciência, 271 p, 2004.

Submetido em 5 de julho de 2017 Aceito em 5 de outubro de 2018 